\title{
A Rapid, Sensitive, and Cost-Efficient Assay to Estimate Viability of Potato Cyst Nematodes
}

\author{
Sven van den Elsen, Maaike Ave, Niels Schoenmakers, Renske Landeweert, Jaap Bakker, and Johannes Helder
}

First, second, fifth, and sixth authors: Laboratory of Nematology, Department of Plant Sciences, Wageningen University, Droevendaalsesteeg 1, 6708 PB Wageningen, The Netherlands; and third and fourth authors: BLGG AgroXpertus, Binnenhaven 56709 PD, 6709 PA Wageningen, The Netherlands.

Accepted for publication 20 September 2011.

\begin{abstract}
van den Elsen, S., Ave, M., Schoenmakers, N., Landeweert, R., Bakker, J., and Helder, J. 2012. A rapid, sensitive, and cost-efficient assay to estimate viability of potato cyst nematodes. Phytopathology 102:140-146.

Potato cyst nematodes (PCNs) are quarantine organisms, and they belong to the economically most relevant pathogens of potato worldwide. Methodologies to assess the viability of their cysts, which can contain 200 to 500 eggs protected by the hardened cuticle of a dead female, are either time and labor intensive or lack robustness. We present a robust and cost-efficient viability assay based on loss of membrane integrity upon death. This assay uses trehalose, a disaccharide present at a high concen-

tration in the perivitelline fluid of PCN eggs, as a viability marker. Although this assay can detect a single viable egg, the limit of detection for regular field samples was higher, $\approx 10$ viable eggs, due to background signals produced by other soil components. On the basis of 30 nonviable PCN samples from The Netherlands, a threshold level was defined $\left(\Delta \mathrm{A}_{\text {trehalose }}=0.0094\right)$ below which the presence of $>10$ viable eggs is highly unlikely (true for $\approx 99.7 \%$ of the observations). This assay can easily be combined with a subsequent DNA-based species determination. The presence of trehalose is a general phenomenon among cyst nematodes; therefore, this method can probably be used for (for example) soybean, sugar beet, and cereal cyst nematodes as well.
\end{abstract}

Routine detection of specific plant pathogens in plant and soil samples is currently shifting from morphology-based inspection toward identification by means of specific DNA sequence signatures. The use of DNA for identification has several advantages; it is life stage independent, large and numerous plant or soil tissue samples can be handled in a short period of time (within days instead of weeks or months; lower chance of false negatives, especially in the case of low infestation levels), and these routine analyses can be done by people without a thorough classical phytopathological background. Downsides of this relatively novel approach are the costs of consumables and equipment.

A potential pitfall of DNA sequence-signature-based pathogen identification is related to the stability of this polymer. Contrary to RNA, for instance, DNA is a relatively stable molecule. Keeping in mind that both phyllosphere and soil are biodiverse, densely inhabited, and competitive habitats, any unprotected food source such as dead bacteria, fungi, or nematodes will be degraded in a relatively short time span. In one of the very few papers on this topic, MacMillan et al. (19) determined the half life of DNA from a nematode (infective Dauer larvae of Phasmarhabditis hermaphrodita) in a sandy loam soil at $\approx 2.5$ days. This could be different in the case of protected structures such as encysted nematodes. Here, we focus on the viability of cysts from the potato cyst nematodes (PCNs) Globodera pallida and $G$. rostochiensis. Being oligophagous obligate parasites of seasonal Solanaceous plant species such as tuber-bearing Solanum spp., they have to survive for a period of at least a few months in the absence of living host plants. PCNs have solved this problem by cyst formation. A cyst is a spherical or lemon-shaped, semipermeable holder that contains up to a few hundred nematode eggs. These eggs are surrounded by a chitinous cell wall. Within the

Corresponding author: J. Helder; E-mail address: Hans.Helder@wur.nl

http://dx.doi.org/10.1094/PHYTO-02-11-0051

(C) 2012 The American Phytopathological Society eggs, first- or second-stage juveniles ( $\mathrm{J} 1$ or $\mathrm{J} 2$ ) will survive in a partly dehydrated condition because they are surrounded by a perivitelline fluid containing $\approx 0.34 \mathrm{M}$ trehalose (24). Trehalose ( $\alpha$-D-glucopyranosyl- $\alpha$-D-glucopyranoside) is a nonreducing disaccharide that, at high concentrations, allows for the desiccation of the nematode while preserving its membrane integrity. Trehalose is a very stable disaccharide; no degradation was observed upon heating a $4 \%(\mathrm{wt} / \mathrm{vol})$ solution to $100^{\circ} \mathrm{C}$ for $24 \mathrm{~h}$ at $\mathrm{pH} 3.5$ to 10 (11).

Trehalose-mediated cryptobiotic life stages are not unique among cyst nematodes; they have been documented for numerous other nematode species of genera Tardigrades, Rotifers, and Crustacea (23). In the case of PCNs, hatching occurs (once diapause is broken) upon exposure to host plant-released eclepins (20), and is preceded by a loss of solutes (including trehalose) from the perivitelline fluid (7).

Although unhatched $\mathrm{J} 2 \mathrm{~s}$ encapsulated in cysts can survive in soil for a prolonged period, each year a part will die because of spontaneous hatching (hatching in absence of a host plant) and another part will die by starvation or other causes such as fungal attack (in-egg mortality). The natural decline of PCN populations was estimated to be $\approx 50$ to $60 \%$ for the first year $(8,9)$; in the second year (keeping the field site fallow for another year), the viability of the remaining eggs decreased by $\approx 40 \%$ (9). In a field experiment in Ireland with $G$. rostochiensis, spontaneous hatch accounted for $\approx 80 \%$ of the mortality, whereas $\approx 20 \%$ could be attributed to in-egg mortality (9).

Around the world, both species of PCN have quarantine status. In many countries, seed potato may be grown only if the foreseen growing area does not contain detectable levels of viable $G$. pallida or G. rostochiensis cysts, or, more accurately, cysts containing at least one viable, unhatched juvenile that is-upon hatching - able to infect a susceptible host. Increasingly, DNAbased detection tests are applied in cyst sample analyses for statutory preplant surveys. PCN-derived DNA signals show that living nematodes are present, or were present in the recent past. 
Especially in the case of in-egg mortality, it is conceivable that PCN DNA will still be detectable even though the nematodes inside are nonviable. To reduce the risk that samples on the basis of their DNA content test positive when they are, in fact, nonviable, DNA-based analysis of cyst samples of PCNs should be combined with a viability test.

Exposure to potato (or tomato) root leachate is an accepted method to check for egg viability (2). However, this test is too labor intensive and takes too much time for routine analyses (see Materials and Methods). Therefore, service laboratories assess the viability of crushed cysts on the basis of the morphology of nonhatched J2s (occasionally, viability stains such as MTTformazan are used; 14). Standardization of these microscopic determinations has been proven to be difficult. High sample throughput in service laboratories (10 to $100 \times 10^{3}$ samples each year) requires a more robust, objective, and preferably automatable test for rapid analysis of soil samples on PCN cyst viability. Here, we present an assay that uses trehalose as a viability marker. It is sensitive, robust, cost-efficient, and fast, and can easily be combined with a subsequent polymerase chain reaction (PCR) for species determination.

\section{MATERIALS AND METHODS}

PCN populations. Populations of G. rostochiensis (R11-7A) and G. pallida (D383 and Rookmaker [Rook 1-2b-Pa3]) were reared on the susceptible potato "Eigenheimer" in a greenhouse at $18^{\circ} \mathrm{C}$ and 16 -h day length. Cysts were collected $\approx 3$ months post inoculation, air dried, and kept at $4^{\circ} \mathrm{C}$ for at least 6 months (to lift diapause). Thereafter, hatchability was determined upon incubation in potato root diffusate (PRD; 15). Batches of fully viable cysts were stored at $-80^{\circ} \mathrm{C}(10)$. A fully viable cyst is defined here by the hatchability of that cyst immediately after lifting diapause, given that it was grown under optimal conditions on a fully susceptible host.

In addition, cysts from $G$. pallida populations E400 1042, P 35 L1040, P 58 L1040, and P 59 L1040 were kindly supplied by Dr. T. van der Lee (Plant Research International, Wageningen, The Netherlands). Viability of these $G$. pallida populations was quantified as described above.

Nonviable PCN batches were kindly supplied by NAK Emmeloord (The Netherlands). These cysts were selected from soil samples collected from potato-growing areas in The Netherlands in the framework of statutory preplant surveys. On the basis of microscopic inspection as described in the European and Mediterranean Plant Protection Organization (EPPO) guideline PM 7/40 (2), three categories of nonviable cyst material were distinguished by the supplier: empty cysts, cysts with unidentifiable content, and cysts with dead larvae.

Essentially trehalose-free, nonviable cysts required as biological background for trehalose detection experiments were prepared by heating $\left(99^{\circ} \mathrm{C}\right) \approx 600$ cysts from $G$. pallida population Rookmaker (Rook 1-2b-Pa3) in $50 \mathrm{ml}$ of MilliQ water for $30 \mathrm{~min}$. Subsequently, the supernatant was removed and replaced by another $50 \mathrm{ml}$ of MilliQ water. After 2 days (at room temperature), the supernatant was removed again, and the batch of nonviable cysts was rinsed another two times with $50 \mathrm{ml}$ of MilliQ. Subsequently, hand-picked dead PCN cysts were (i) used in an experiment to test the amplifiability of DNA extracted from dead cysts upon exposure to soil and (ii) mixed with viable cysts or eggs in the ratios required for testing.

Trehalose quantification. Single or multiple cysts, eggs, or both were transferred to a $0.2-\mathrm{ml}$ PCR tube containing $10 \mu \mathrm{l}$ of water (MilliQ quality). Trehalose was extracted from the nematode eggs by incubating the cysts for $30 \mathrm{~min}$ at $99^{\circ} \mathrm{C}$ using a thermocycler (MJ Biorad) or a Thermomixer (Eppendorf, Hamburg, Germany) (or similar heating device). For the crushing of cysts, a pestle was prepared by flaming the end of a $200-\mu$ l pipette tip. After trehalose extraction from cysts by heating or crushing, samples were cooled down to room temperature and immediately processed further or stored at $-20^{\circ} \mathrm{C}$.

A detection kit (K-TREH 01/09 from Megazyme International Ireland Ltd., Wicklow, Ireland) was used to quantify the trehalose content of PCN cysts. In essence, trehalose is hydrolyzed to two units of D-glucose by trehalase. At the recommended $\mathrm{pH} 5.5$, this trehalase of prokaryotic origin is active up to $40^{\circ} \mathrm{C}$. D-glucose is phosphorylated by hexokinase in the presence of ATP. The resulting glucose-6-phosphate is oxidized by glucose-6-phosphate dehydrogenase and $\mathrm{NADP}^{+}$to gluconate-6-phosphate, NADPH, and $\mathrm{H}^{+}$. Subsequently, the NADPH concentration is measured spectrophotometrically at $\lambda=340 \mathrm{~nm}$. A NanoDrop 1000 (Wilmington, DE) was used to quantify the increase in absorbance (it can be replaced by any other spectrophotometer).

To each of the sample extracts (volume $\approx 10 \mu \mathrm{l}$ ), $12 \mu \mathrm{l}$ of MilliQ water, $2 \mu \mathrm{l}$ of imidazole buffer $(2 \mathrm{M}, \mathrm{pH} 7.0)$ with $100 \mathrm{mM}$ $\mathrm{MgCl}_{2}, 1 \mu \mathrm{l}$ of a NADP + ATP solution $(12.5+36.7 \mu \mathrm{g} / \mu \mathrm{l})$, and $0.2 \mu \mathrm{l}$ of hexokinase and glucose-6-phosphate dehydrogenase ( 0.425 and $0.212 \mathrm{U} / \mu \mathrm{l}$, respectively) were added. Samples were vortexed and cleared by centrifugation at $12,000 \mathrm{rpm}$ for a few seconds. After $\approx 5 \mathrm{~min}$, the absorbance at $\lambda=340 \mathrm{~nm}$ was measured $\left(\mathrm{A}_{1}\right)$. Subsequently, $1 \mu \mathrm{l}$ of trehalase solution was added $(0.490 \mathrm{U} / \mu \mathrm{l})$ and the solution was vortexed again, followed by centrifugation for a few seconds at $12,000 \mathrm{rpm}$. After incubation for at least $5 \mathrm{~min}$ at room temperature, the absorbance of the supernatant was measured at $340 \mathrm{~nm}$ using a NanoDrop $\left(\mathrm{A}_{2}\right)$.

DNA extraction and ribosomal DNA amplification. In order to test whether the proposed trehalose-based viability assay is compatible with DNA-based species identification and, if so, whether a viability assay should precede or follow a species determination, cysts were crushed by use of homemade pestles that were prepared by flaming the end of a $200-\mu \mathrm{l}$ pipette tip. Lysis was performed by adding an equal volume (mostly $10 \mu \mathrm{l}$ ) of lysis buffer containing $\beta$-mercaptoethanol ( $1 \%$ [vol/vol]), and proteinase-K $(800 \mu \mathrm{g} / \mathrm{ml})$ as described by Holterman et al. (12). Lysis took place in a Thermomixer (Eppendorf) at $65^{\circ} \mathrm{C}$ and $750 \mathrm{rpm}$ for $2 \mathrm{~h}$, followed by $5 \mathrm{~min}$ of incubation at $100^{\circ} \mathrm{C}$. Lysate was used immediately or stored at $-20^{\circ} \mathrm{C}$. Before PCR, cyst lysate was diluted 100 times with MilliQ water. PCR was performed on $3 \mu \mathrm{l}$ of (diluted) template in a total reaction volume of $25 \mu$ l. Speciesspecific PCR was essentially performed as described in EPPO guideline PM 7/40 (2), protocol D (2). This protocol exploits species-specific motives in the large-subunit ribosomal DNA. Amplification products $(2 \mu \mathrm{l})$ were run on a $1.5 \%$ agarose gel stained with GelStar ( $2 \mu \mathrm{l}$ per $100 \mathrm{ml}$ ) (Lonza, Rockland). To assess the size of the PCR products, $1 \mu \mathrm{l}$ of a $1-\mathrm{kb}$ Plus DNA Ladder (Invitrogen, Carlsbad, CA) was included.

Amplifiability of DNA extracted from dead cysts. To test for changes in the amplifiability of DNA extracted from dead PCN cysts (killed by heating in water, see section "PCN populations") over time upon exposure to sandy soil from an agricultural field nearby Wageningen, individual cysts were buried in petri dish $(9 \mathrm{~cm}$, eight cysts per dish). To facilitate recollection of cysts, they were individually glued to the tip of a hair. At several time points (between 0 and 51 days after burying of the cysts in sandy soil), cysts were recollected and tested for amplifiable DNA as described above. Petri dishes with soil and cysts were kept at $18^{\circ} \mathrm{C}$ in the dark. Dishes were weighed every week, and loss in weight due to water evaporation was compensated for by the addition of an equivalent volume of tap water.

\section{RESULTS}

Extraction of trehalose from PCN cysts. Unhatched PCN juveniles are surrounded by a physically strong, chitinous egg wall, and several approaches were tested to quantitatively extract trehalose from cysts. We tested single treatments or combinations 
of two of the following treatments: crushing, microwave, heating, and combination of heating and shaking (Table 1). Combinations 1 and 3 resulted in the highest trehalose concentrations in combination with limited variation between cysts. Combination 2 gave high trehalose concentrations per cyst but the consistency among individual cysts was low. This may have been due to crushing, a manual treatment that is difficult to standardize. When combinations 3 and 4 were compared, the same phenomenon was observed. Treatment 5 (microwave) resulted in barely any signal. In combination 6 , the detected trehalose could be attributed fully to the crushing of the PCN cysts. Combination 7 showed the effect of incubation of cysts in water at room temperature; the trehalose values did not significantly differ from zero. Combination 1 (30 min of shaking at $99^{\circ} \mathrm{C}$ in water) resulted in the most efficient and consistent extraction of trehalose from PCN cysts; therefore, it was selected as the preferred method for further experimentation.

Trehalose levels in PCN populations with various viabilities. For five G. pallida populations, a comparison was made between hatchability values determined in a regular hatching assay and the viabilities as suggested by the trehalose quantities extracted from individual cysts (Table 2A and B). G. pallida population D383 was arbitrarily selected as a fully viable reference population. Apart from the viability, the quantity of trehalose released from a single cyst depends on the number of eggs it contains. Because the number of eggs per cyst may vary considerably (3), the quantity of trehalose extracted from a fully viable cyst may vary as well. This natural variation explains the $>100 \%$ viability value

TABLE 1. Comparison of methods for the extraction of trehalose from single potato cyst nematode cysts (Globodera pallida) ${ }^{\mathrm{a}}$

\begin{tabular}{|c|c|c|c|c|c|c|c|}
\hline \multirow[b]{2}{*}{ Treatment } & \multicolumn{7}{|c|}{ Extraction method } \\
\hline & 1 & 2 & 3 & 4 & 5 & 6 & 7 \\
\hline Crushing & - & + & - & + & - & + & $\ldots$ \\
\hline Microwave (700W, $1 \mathrm{~min})$ & $\ldots$ & $\ldots$ & $\ldots$ & $\ldots$ & + & + & $\ldots$ \\
\hline Heating $\left(30 \mathrm{~min}\right.$ at $\left.99^{\circ} \mathrm{C}\right)$ & $\ldots$ & $\ldots$ & + & + & $\ldots$ & $\ldots$ & $\ldots$ \\
\hline Heating and shaking $\left(30 \mathrm{~min}\right.$ at $\left.99^{\circ} \mathrm{C}, 900 \mathrm{rpm}\right)$ & + & + & $\ldots$ & $\ldots$ & $\ldots$ & $\ldots$ & $\ldots$ \\
\hline \multirow[t]{2}{*}{ Average trehalose content $(\mu \mathrm{g})$ per cyst $(n=3)$} & 2.01 & 1.46 & 1.95 & 1.96 & 0.03 & 1.86 & 0.03 \\
\hline & $\sigma_{\mathrm{n}-1}=0.025$ & $\sigma_{\mathrm{n}-1}=0.900$ & $\sigma_{\mathrm{n}-1}=0.012$ & $\sigma_{\mathrm{n}-1}=0.112$ & $\sigma_{\mathrm{n}-1}=0.044$ & $\sigma_{\mathrm{n}-1}=0.030$ & $\sigma_{\mathrm{n}-1}=0.017$ \\
\hline
\end{tabular}

${ }^{a}$ Methods 1, 3, and 5 are single treatments, whereas methods 2, 4, and 6 consist of a combination of two treatments (method 7 is the untreated control).

TABLE 2. Comparison between a conventional and trehalose-based viability test of cysts from the potato cyst nematode (PCN) Globodera pallida ${ }^{\text {a }}$

\begin{tabular}{|c|c|c|c|c|c|c|c|c|c|}
\hline A. PCN population & $\begin{array}{c}\text { Viability } \\
\text { (hatching } \\
\text { assay) (\%) }\end{array}$ & $n$ & Cyst size & & & $\begin{array}{c}\left(\mathrm{A}_{2}-\mathrm{A}_{1}\right)-\Delta \mathrm{A}_{\text {blank }} \\
=\Delta \mathrm{A}_{\text {trehalose }} \mathrm{b}^{\mathrm{m}}\end{array}$ & $\begin{array}{c}\text { [Trehalose] } \\
(\mu \mathrm{g} / \mu \mathrm{l})^{\mathrm{c}}\end{array}$ & $\begin{array}{l}\text { Trehalose/ } \\
\text { cyst }(\mu \mathrm{g})^{\mathrm{d}}\end{array}$ & $\begin{array}{c}\text { Average } \\
\text { viability } \\
(\%)\end{array}$ \\
\hline \multirow[t]{3}{*}{ D383 } & 100 & 10 & Small & & & $\begin{array}{l}0.3476^{\text {Avg }} \\
(0.062)\end{array}$ & $\begin{array}{l}0.0945^{\text {Avg }} \\
(0.017)\end{array}$ & $\begin{array}{l}2.47^{\text {Avg }} \\
(0.44)\end{array}$ & - \\
\hline & 100 & 10 & Medium & & & $\begin{array}{l}0.3781^{\text {Avg }} \\
(0.016)\end{array}$ & $\begin{array}{l}0.1027^{\text {Avg }} \\
(0.004)\end{array}$ & $\begin{array}{l}2.67^{\text {Avg }} \\
(0.11)\end{array}$ & - \\
\hline & 100 & 10 & Large & & & $\begin{array}{l}0.3760^{\mathrm{Avg}} \\
(0.009)\end{array}$ & $\begin{array}{l}0.1036^{\mathrm{Avg}} \\
(0.003)\end{array}$ & $\begin{array}{l}2.72^{\text {Avg }} \\
(0.07)\end{array}$ & - \\
\hline Total & - & 30 & - & & & - & - & $\begin{array}{l}2.62^{\text {Avg }} \\
(0.28)\end{array}$ & 100 \\
\hline Blank $^{b}$ & - & 4 & - & & & $\begin{array}{l}0.0013^{\mathrm{Avg}} \\
(0.0015)\end{array}$ & - & - & - \\
\hline Inactivated trehalase $\mathrm{e}^{\mathrm{e}}$ & - & 7 & - & & & $\begin{array}{l}-0.0014^{\text {Avg }} \\
(0.0022)\end{array}$ & - & - & - \\
\hline B. PCN population & $\begin{array}{c}\text { Viability } \\
\text { (hatching } \\
\text { assay) (\%) }\end{array}$ & $n$ & Cyst & $\mathrm{A}_{1}$ & $\mathrm{~A}_{2}$ & $\begin{array}{c}\left(\mathrm{A}_{2}-\mathrm{A}_{1}\right)-\Delta \mathrm{A}_{\text {blank }} \\
\quad=\Delta \mathrm{A}_{\text {trehalose }} \mathrm{b}\end{array}$ & $\begin{array}{c}\text { [Trehalose] } \\
(\mu \mathrm{g} / \mu \mathrm{l})^{\mathrm{c}}\end{array}$ & $\begin{array}{l}\text { Trehalose/ } \\
\text { cyst }(\mu \mathrm{g})^{\mathrm{d}}\end{array}$ & $\begin{array}{c}\text { Average } \\
\text { viability } \\
(\%)\end{array}$ \\
\hline \multirow[t]{4}{*}{ E400 1042} & 100 & 1 & 1 & 0.052 & 0.482 & 0.432 & 0.117 & 3.07 & 116 \\
\hline & $\ldots$ & $\ldots$ & 2 & 0.048 & 0.473 & 0.427 & 0.116 & 3.04 & \\
\hline & $\ldots$ & $\ldots$ & 3 & 0.050 & 0.475 & 0.427 & 0.116 & 3.04 & \\
\hline & $\ldots$ & $\ldots$ & 4 & 0.042 & 0.464 & 0.424 & 0.115 & 3.02 & \\
\hline \multirow[t]{4}{*}{ P 58 L1040 } & 50 & 1 & 1 & 0.035 & 0.456 & 0.423 & 0.115 & 3.01 & 46 \\
\hline & $\ldots$ & $\ldots$ & 2 & 0.031 & 0.030 & 0.001 & 0.000 & 0.01 & \\
\hline & $\ldots$ & $\ldots$ & 3 & 0.025 & 0.259 & 0.236 & 0.064 & 1.68 & \\
\hline & $\ldots$ & $\ldots$ & 4 & 0.024 & 0.025 & 0.003 & 0.001 & 0.02 & \\
\hline \multirow[t]{4}{*}{ P 35 L 1040} & 30 & 1 & 1 & 0.023 & 0.026 & 0.005 & 0.001 & 0.04 & 27 \\
\hline & $\ldots$ & $\ldots$ & 2 & 0.022 & 0.020 & 0.000 & 0.000 & 0.00 & \\
\hline & $\ldots$ & $\ldots$ & 3 & 0.037 & 0.420 & 0.385 & 0.105 & 2.74 & \\
\hline & $\ldots$ & $\ldots$ & 4 & 0.024 & 0.023 & 0.001 & 0.000 & 0.01 & \\
\hline \multirow[t]{4}{*}{ P 59 L1040 } & 0 & 1 & 1 & 0.025 & 0.022 & -0.001 & 0.000 & -0.01 & 0 \\
\hline & $\ldots$ & $\ldots$ & 2 & 0.023 & 0.021 & 0.000 & 0.000 & 0.00 & \\
\hline & $\ldots$ & $\ldots$ & 3 & 0.024 & 0.020 & -0.002 & -0.001 & -0.01 & \\
\hline & $\ldots$ & $\ldots$ & 4 & 0.031 & 0.024 & -0.005 & -0.001 & -0.04 & \\
\hline Blank $^{\mathrm{b}}$ & - & - & - & 0.018 & 0.016 & -0.002 & - & - & - \\
\hline
\end{tabular}

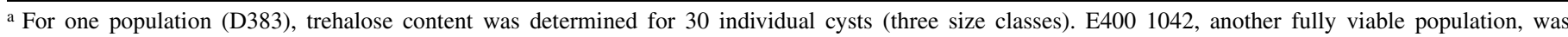
included to show possible population effects. P58 L1040, P35 L1040, and P59 L1040 show various degrees of reduced viability using single cysts for trehalose determinations).

${ }^{\mathrm{b}} \Delta \mathrm{A}_{\text {blank }}=\mathrm{A}_{2}-\mathrm{A}_{1}$ (complete test without cyst). Avg. = average and numbers in parentheses = standard deviation.

${ }^{c}[$ Trehalose $]=\Delta \mathrm{A}_{\text {trehalose }} \times\left(\mathrm{MW}_{\text {trehalose }} / \varepsilon \times \mathrm{D} \times 2\right)(\mathrm{in} \mu \mathrm{g} / \mu \mathrm{l})$. Avg. $=$ average and numbers in parentheses $=$ standard deviation.

$\mathrm{d}$ Trehalose per cyst $=$ [trehalose $] \mu \mathrm{g} / \mu \mathrm{l} \times 26.2($ in $\mu \mathrm{g})$. Avg. $=$ average and numbers in parentheses $=$ standard deviation.

e Trehalase inactivated by $15 \mathrm{~min}$ of incubation at $95^{\circ} \mathrm{C}$. 
for cysts from population E400 1042. For moderately viable populations such as P58 L1040 and P35 L1040, striking differences in the trehalose contents of individual cysts were observed (Table $2 \mathrm{~B})$. It suggests that such a population is a mixture of nonviable

TABLE 3. Trehalose contents of cysts and cyst-like material scored as nonviable $^{\mathrm{a}}$

\begin{tabular}{|c|c|c|}
\hline$\underline{\text { Sample ID }^{\mathrm{b}}}$ & Sample volume $(\mu \mathrm{l})$ & $\Delta \mathrm{A}_{\text {trehalose }} \mathrm{e}^{\mathrm{c}}$ \\
\hline A1 & 72 & 0.003 \\
\hline A2 & 72 & 0.000 \\
\hline A3 & 65 & 0.001 \\
\hline A4 & 62 & 0.001 \\
\hline A5 & 45 & 0.000 \\
\hline A6 & 42 & 0.000 \\
\hline A7 & 66 & -0.001 \\
\hline A8 & 74.5 & 0.002 \\
\hline A9 & 65 & -0.001 \\
\hline A10 & 71.5 & -0.003 \\
\hline B1 & 86.5 & 0.005 \\
\hline B2 & 116 & 0.003 \\
\hline B3 & 79.5 & 0.000 \\
\hline B4 & 118 & 0.003 \\
\hline B5 & 100 & 0.005 \\
\hline B6 & 22.5 & 0.005 \\
\hline B7 & 140 & 0.001 \\
\hline B8 & 64 & 0.004 \\
\hline B9 & 60 & 0.003 \\
\hline B10 & 97 & -0.005 \\
\hline $\mathrm{C} 1$ & 110 & -0.001 \\
\hline $\mathrm{C} 2$ & 57 & 0.000 \\
\hline C3 & 70.5 & 0.001 \\
\hline $\mathrm{C} 4$ & 54 & 0.000 \\
\hline C5 & 54.5 & -0.001 \\
\hline C6 & 85 & 0.002 \\
\hline $\mathrm{C} 7$ & 72.5 & 0.005 \\
\hline C8 & 24.5 & -0.003 \\
\hline C9 & 67.5 & 0.001 \\
\hline $\mathrm{C} 10$ & 115 & 0.007 \\
\hline
\end{tabular}

${ }^{a}$ Samples were randomly taken in early spring 2010 from statutory preplant surveys throughout The Netherlands. Upon crushing of cysts and cyst-like material, three categories were distinguished: empty cysts (A), cysts with unidentifiable content (B), and cysts with dead larvae (C). The condition of this degraded cyst material did not allow for a species determination anymore. Samples were kindly supplied by NAK Emmeloord (The Netherlands).

$\mathrm{b} \overline{\mathrm{x}}$ (category A) $0.000, \sigma_{\mathrm{n}-1}=0.002, \overline{\mathrm{x}}$ (category B) $0.002, \sigma_{\mathrm{n}-1}=0.003$, and $\overline{\mathrm{x}}$ (category $\mathrm{C}$ ) $0.001, \sigma_{\mathrm{n}-1}=0.003$.

c $\Delta \mathrm{A}_{\text {trehalose }}=\left(\mathrm{A}_{2}-\mathrm{A}_{1}\right)-\Delta \mathrm{A}_{\text {blank }}$. and viable cysts (and not a homogeneous population of cysts with intermediately viabilities). However, the number of observations was too low to draw any firm conclusion. It is noted that the viability values for PCN populations as determined by trehalose measurements do not deviate substantially from the viabilities established on the basis of hatchability.

Trehalose levels in nonviable natural PCN samples. For practical, often quarantine status-related purposes, $\mathrm{PCN}$ viability tests are used qualitatively (= presence or absence of infectious nematodes). To determine a threshold above which a trehalose signal is pointing at the presence of viable PCN cysts, three categories of nonviable cyst and cyst-like samples were screened. All samples were selected from statutory preplant surveys in potato-growing areas throughout The Netherlands. The condition of this (partially) degraded cyst material made it impossible to perform a species determination. The average $\Delta \mathrm{A}_{\text {trehalose }}$ was 0.000 for empty cysts $(n=10), 0.003$ for cysts with a nonidentifiable content $(n=10)$, and 0.003 for cysts with dead larvae $(n=10)$ (Table 3). Standard deviation within each of the categories was 0.002 to 0.003 . The highest $\Delta \mathrm{A}_{\text {trehalose }}$ value for nonviable PCN material was 0.007 (category $C$, sample 10). A Shapiro-Wilk test was performed to test whether these 30 samples represent a continuum of natural cyst degradation (cysts with dead larvae $\rightarrow$ cysts with a nonidentifiable content $\rightarrow$ empty cysts) that came from a normally distributed population. This test of normality gave a $P$ value of 0.570 with an $\alpha$ level of 0.05 . It was concluded that the data do not deviate from a normally distributed population. Given that $\approx 99.7 \%$ of a normal distribution lies within three standard deviations of the mean $(x=0.0012, \sigma=0.00273)$, we propose a threshold value for $\Delta \mathrm{A}_{\text {trehalose }}$ of 0.0094 .

Detection threshold of the trehalose-based viability assay. In order to verify whether a trehalose-based viability assay can be used for the detection of low quantities of viable (= infectious) PCN cysts or eggs as such or against a background of nonviable cysts, four series of samples were created. Series 1 (1, 5, and 25 viable cysts) gave a clear trehalose signal pointing at the presence of viable PCN eggs (Table 4). It is noted that the small extraction volume $(10 \mu \mathrm{l})$ hinders a proper quantitative extraction of trehalose. The second series showed that a single viable cyst in a background of 24 nonviable cysts can be detected without any problem. In the third series, the trehalose signals from 1 to 20 viable PCN eggs were determined. It was shown that 10 or 20 viable egg produced a trehalose signal above the viability threshold defined at $\Delta \mathrm{A}_{\text {trehalose }}=0.0094$. Single $\mathrm{PCN}$ eggs produced small

TABLE 4. Detection of trehalose in cysts or eggs of the potato cyst nematode (PCN) Globodera pallida (Rookmaker) ${ }^{\mathrm{a}}$

\begin{tabular}{|c|c|c|c|c|c|c|c|}
\hline \multirow[b]{2}{*}{ Series } & \multicolumn{3}{|c|}{ Number of } & \multirow[b]{2}{*}{$\mathrm{A}_{1}$} & \multirow[b]{2}{*}{$\mathrm{A}_{2}$} & \multirow[b]{2}{*}{$\Delta \mathrm{A}$} & \multirow[b]{2}{*}{ Viable PCN cysts or eggs ${ }^{b}$} \\
\hline & Viable cysts & Nonviable cysts & Viable eggs & & & & \\
\hline \multirow[t]{2}{*}{1} & 25 & & & 0.343 & 0.509 & 0.166 & $\mathrm{P}$ \\
\hline & 5 & & & 0.074 & 0.400 & 0.326 & $\mathrm{P}$ \\
\hline \multirow[t]{3}{*}{2} & 10 & 15 & & 0.152 & 0.411 & 0.259 & $\mathrm{P}$ \\
\hline & 5 & 20 & & 0.149 & 0.418 & 0.269 & $\mathrm{P}$ \\
\hline & 1 & 24 & & 0.062 & 0.267 & 0.205 & $\mathrm{P}$ \\
\hline \multirow{4}{*}{3} & & & 1 & 0.017 & 0.019 & 0.002 & (P) \\
\hline & & & 1 & 0.015 & 0.022 & 0.007 & (P) \\
\hline & & & 1 & 0.016 & 0.021 & 0.005 & (P) \\
\hline & & & 1 & 0.016 & 0.021 & 0.005 & (P) \\
\hline \multirow[t]{2}{*}{4} & & 25 & 20 & 0.052 & 0.075 & 0.023 & $\mathrm{P}$ \\
\hline & & 25 & 10 & 0.054 & 0.071 & 0.017 & $\mathrm{P}$ \\
\hline
\end{tabular}

a Absorbance (A) refers to absorbance at a wavelength of $340 \mathrm{~nm}$. Samples with a $\Delta \mathrm{A}<0.0094$ were scored as not detected. P indicates presence of viable cyst or eggs as $\Delta \mathrm{A}$ exceeds threshold value. $\Delta \mathrm{A}_{\text {trehalose }}=\left(\mathrm{A}_{2}-\mathrm{A}_{1}\right)-\Delta \mathrm{A}_{\text {blank }}$.

${ }^{b}(\mathrm{P})$ indicates that, although single eggs consistently gave small but consistent trehalose signals, they did not exceed the threshold. This is explained by the relatively clean nature of eggs samples as compared to the field samples analyzed in Table 3. 
but consistent trehalose signals, but these signals did not reach the threshold level. It is noted that the threshold was defined on the basis of field samples with considerable background noise. Such noise was substantially reduced in the case of isolated cysts. In series 4 , viable eggs were mixed with 25 nonviable cysts, and also here the resulting $\Delta \mathrm{A}_{\text {trehalose }}$ were above the viability threshold (Table 4). Single eggs were not included in this series, because they were not expected to produce a signal above the threshold. In principle (i.e., when single isolated eggs are assayed), the newly developed trehalose-based viability assay is sufficiently sensitive to detect a single viable egg. However, in the case of field samples, the detection limit will be $\approx 10$ viable PCN eggs in a background of 25 nonviable PCN cysts.

Compatibility of the trehalose-based viability assay with PCN species determination. If a viability assay points at the presence of viable PCN cysts, it could be relevant to perform a DNA-based species determination consecutively. To test the compatibility of both assays, an experiment was performed with fully viable cysts from a $G$. rostochiensis (R11-7A) and a $G$. pallida population (D383). Initial treatment of single cysts with or without crushing (CR) and with or without lysis buffer (LB) resulted in either the expected trehalose signal without any PCR product (treatments $-\mathrm{CR},-\mathrm{LB}$ and $+\mathrm{CR},-\mathrm{LB}$ ) or with the expected PCR products in combination with a nonfunctioning trehalose assay (treatment $+\mathrm{CR},+\mathrm{LB}$ ) (Table 5; Fig. 1A). It is con- cluded that both crushing and lysis buffer are required for the release of PCR amplifiable DNA, whereas the presence of LB is noncompatible with trehalose determination. However, when LB is added after trehalose measurement, a proper PCR product is amplified (Fig. 1B). Crushing of the cyst is a necessary treatment for DNA extraction. However, this experiments shows that it does not matter whether the crushing takes place before (samples 9 to 12) or after (samples 1 to 4) trehalose determination (Table 5; Fig. 1). PCR primers were designed on species-specific motives in the LSU rDNA (2); the size of the main amplification products was $\approx 450$ bp for $G$. rostochiensis and $\approx 600$ bp for G. pallida.

Amplifiability of DNA from dead PCN cysts. To see whether amplifiable DNA could be extracted from dead intact cysts from the PCN G. pallida upon exposure to a natural agricultural field, dead cysts buried in a petri dish filled with sandy soil were recollected at several time points. This qualitative experiment showed clearly that, even after 51 days direct exposure to soil, some cysts allowed for the amplification of DNA fragment of $\approx 670$ bp (Fig. 2). It is concluded that, in this case of artificial inegg mortality (i.e., killing of unhatched, encysted juveniles by incubation in water at $99^{\circ} \mathrm{C}$ ), the speed of DNA degradation is retarded substantially compared with the degradation of DNA from dead nematodes directly exposed to soil (e.g., Dauer larvae of $P$. hermaphrodita, as mentioned above).

TABLE 5. Compatibility of trehalose viability test with DNA-based species determination for the potato cyst nematode (PCN) species Globodera rostochiensis and G. pallida $a^{\mathrm{a}}$

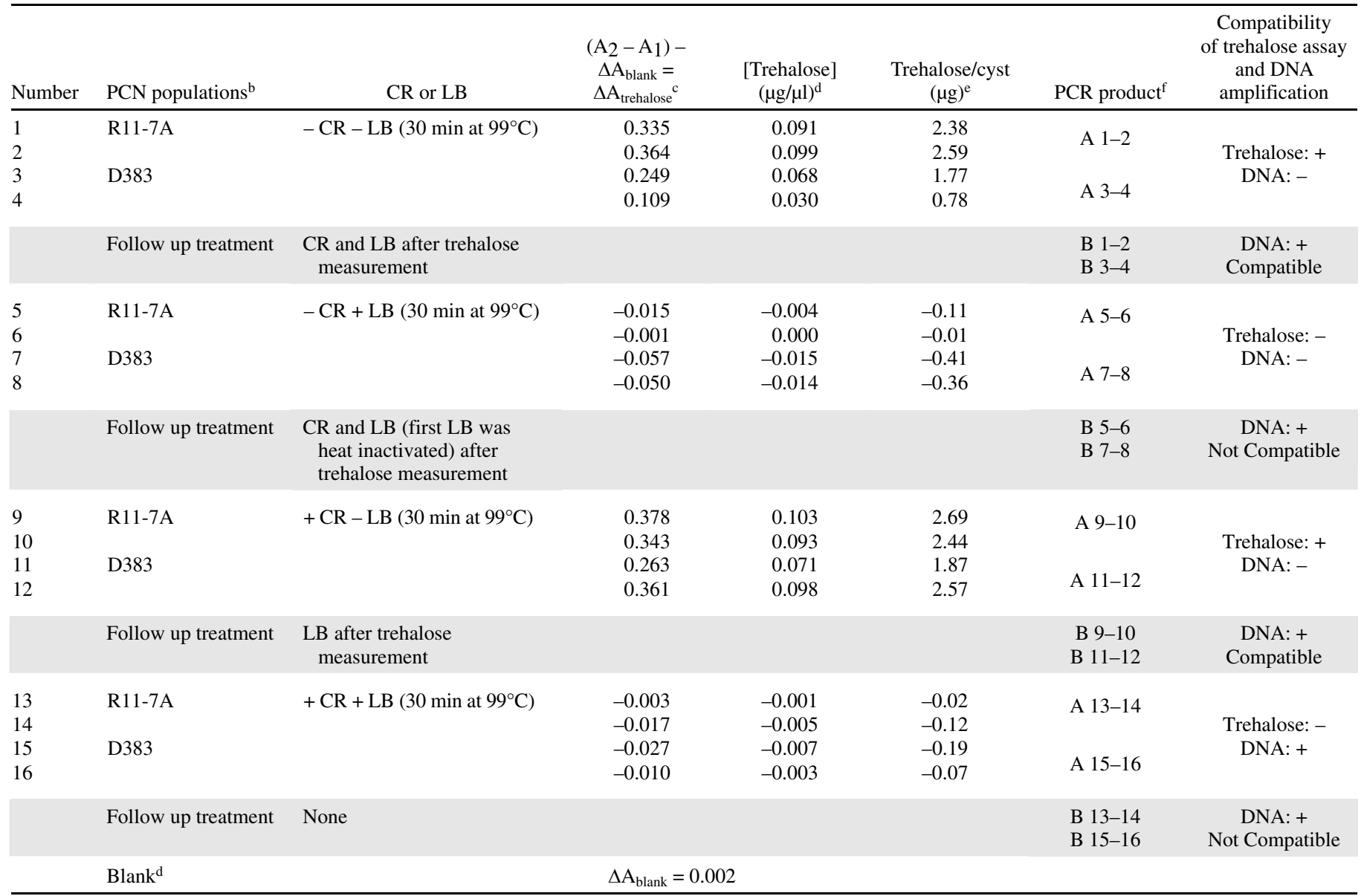

${ }^{a}$ A combination of crushing $(\mathrm{CR})$ and exposure to nematode lysis buffer (LB; 12) is required for DNA extraction. Various treatments and treatment orders were tested (in duplicate).

b Fully viable PCN populations: G. rostochiensis R11-7A and G. pallida D383.

c $\Delta \mathrm{A}_{\text {blank }}=\mathrm{A}_{2}-\mathrm{A}_{1}$ (complete test without cyst).

${ }^{\mathrm{d}}[$ Trehalose $]=\Delta \mathrm{A}_{\text {trehalose }} \times\left(\mathrm{MW}_{\text {trehalose }} / \varepsilon \times \mathrm{D} \times 2\right)($ in $\mu \mathrm{g} / \mu \mathrm{l})$.

e Trehalose per cyst $=[$ trehalose $] \mu \mathrm{g} / \mu \mathrm{l} \times 26.2$ (in $\mu \mathrm{g}$ ).

${ }^{\mathrm{f}} \mathrm{PCR}=$ polymerase chain reaction (Fig. 1 ). 


\section{DISCUSSION}

In parallel with changes in veterinary and humane diagnostics, routine detection of plant pathogens is inevitably shifting toward DNA-based detection. A potential disadvantage of the use of DNA for plant pathogen detection is the stability of this polymer. Even a nonviable pathogen could, for some time, give rise to a positive signal in DNA-based detection assays. Because most pathogens live in highly competitive environments, DNA degradation after death will usually be a matter of hours or days. However, this might be different when pathogens are protected by a reinforced cell wall or the equivalent; physically strong and hard-to-degrade layers surrounding the pathogen in some specialized life stages (e.g., to survive temporary absence of host plants). In those cases, there could be a considerable time lag between viability of the pathogen and DNA detectability. Hence, on particular occasions, it could be useful to accompany a DNA-based detection assay with a viability test.

In the past, a range of viability stains has been tested on both pathogenic and non-plant-pathogenic nematodes. Boyd (4) used an aqueous solution of iodine and potassium iodide to stain dead second-stage larvae of $G$. rostochiensis. For free-living nematode genera Diplogasteroides and Diplogasteritus, eosin-Y dye was employed to identify dead individuals (6). Upon testing a number of stains on eight nematode genera (four plant-parasitic and four nonparasitic), Ogiga and Estey (21) selected two dyes, Meldola Blue and Nile Blue A, as being the more dependable stains for the identification of dead nematodes. However, apart from the laborintensive nature of these assays, none of these stains are suitable for routine use because there clearly is an element of subjectivity in these stain-based viability assessments.

Various viability tests based on DNA stains or other dyes have been developed for bacterial and fungal pathogens. In the case of the chytrid fungus Batrachochytrium dendrobatidis - a fungus implicated in the global decline of amphibians - a combination of

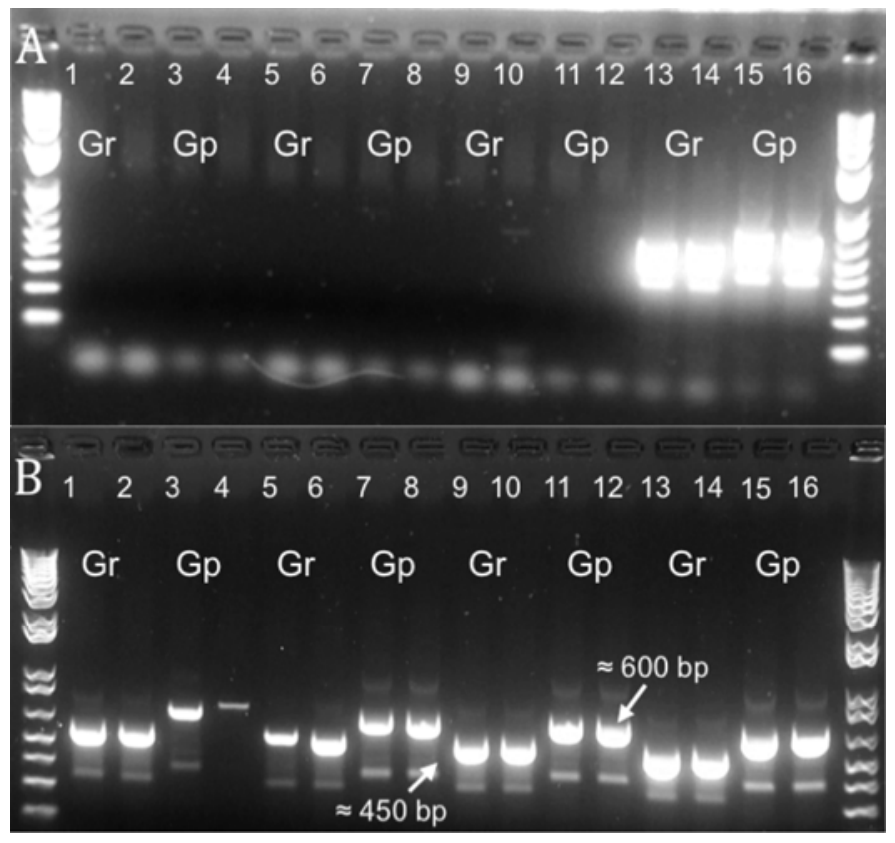

Fig. 1. Compatibility of a trehalose-based viability test with potato cyst nematode species determination. A and B, Amplification products resulting from a polymerase chain reaction (PCR) using large subunit ribosomal DNAbased species-specific primers. A, Samples 1 to 16 as described in Table 5 as used in the trehalose assay. B, The same samples after a follow-up treatment as described in Table 5. On the extreme left and right, a 1-kb Plus DNA Ladder was included. Gr: Globodera rostochiensis, Gp: Globodera pallida. Size of the amplification products appears to differ slightly between A and B, caused by the type of DNA stain used. GelStar, a highly sensitive stain, affects migration of PCR products in a concentration-dependent manner. two fluorescent DNA stains (namely, SYBR14 and propidium iodide) was tested on zoospores. Motile (viable) zoospores stained green, whereas nonviable zoospores turned red (22). Another dye used for viability assays is fluorescein diacetate (FDA). This apolar molecule diffuses across the plasma membrane, and intracellular esterase activity results in the release of optically active fluorescein (13). FDA-based vitality assays depend on the permeability of the cellular structures under investigation. Fungal spore coats are not necessarily permeable to FDA. In the case of teliospores from Tilletia controversa-the causal agent of dwarf bunt in wheat-Chastain and King (5) had to use extracts of teliospores (instead of intact spores).

In most instances, techniques involving viability stains require subsequent microscopic analysis. As an alternative, dyes such as ethidium bromide monoazide (EMA; 18) that block the PCR reaction could be used to detect dead propagules. However, the application of this dye for viability tests is not straightforward. Kobayashi et al. (17) tested this dye to discriminate between viable and dead bacterial cells of Staphylococcus aureus and $S$. epidermidis. For this particular case, EMA was shown to be an unreliable viability agent.

Dye-independent approaches, for example, make use of the intrinsic instability of mRNA. Kaucner and Stinear (16) were among the first to apply this principle to assess the viability of Giardia cysts and Cryptosporidium parvum oocysts (two protozoan parasites) in fresh-water samples. The same principle was exploited to estimate the viability of the opportunistic fungal pathogen Cryptococcus neoformans. Here, both the primers and the internal control were based in the capsular CAP10 gen mRNA. Although this methodology was shown to be specific and sensitive for clinical specimens (1), this application requires relatively expensive materials.

In the case of cysts from PCNs, current viability tests are time consuming and labor intensive (hatching assays; see Materials and Methods) or insufficiently robust (microscopic inspection of crushed cysts or eggs; see Materials and Methods). To avoid any accessibility problem, we set out to develop a viability assay without the use of a dye or molecular probe, yet making use of the loss of selective permeability of membranes upon death. This implies that any measurable component with a steep concentration gradient across the membrane (highest concentration at the inside) could potentially be used as a viability marker. In
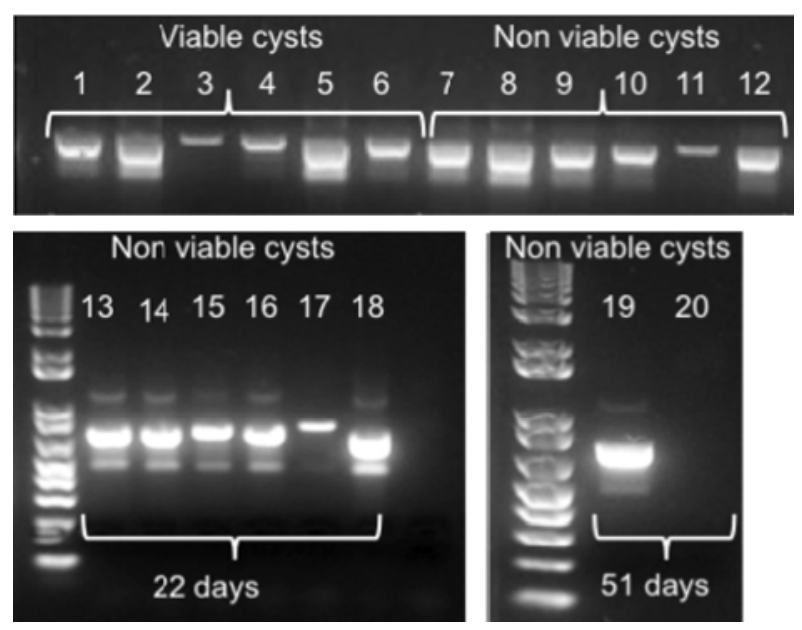

Fig. 2. Amplification of a 674-bp fragment from the large subunit of the ribosomal DNA from Globodera pallida cysts upon heating in water for $30 \mathrm{~min}$ at $99^{\circ} \mathrm{C}$ followed by incubation in a sandy soil taken from a local agricultural field. Samples 1 to 6: six randomly taken fully viable cysts (control). Samples 7 to 12 : six randomly taken cysts just after heat treatment. Samples 13 to 18: six individual cysts recollected after 22 days of direct exposure to soil. Samples 19 to 20: two individual cysts recollected after 51 days of direct exposure to soil. 
the particular case of PCNs, we choose trehalose because of its very high concentration in the perivitelline fluid. Detection of the dissacharide involves only two steps: its hydrolysis into two glucose molecules and, subsequently, the detection of glucose.

Given the small, economical margins in arable farming, the cost-efficiency aspect of this new assay could be relevant (in our hands, US $\$ 0.04$ to 0.07 per sample). It is noted that the total reaction volume for trehalose detection in our experiments remained low $(\approx 25 \mu \mathrm{l})$. This reaction volume can be upscaled according to number of cysts analyzed. Depending on the working volume, a single trehalose detection kit can be used for 1,000 to 10,000 viability tests. To the best of our knowledge, this is the most cost-efficient and straightforward viability assay for plantparasitic nematodes reported so far. We wish to underline that the threshold value for PCN viability as given in this article $\left(\Delta \mathrm{A}_{\text {trehalose }}\right.$ $=0.0094$; below this value the presence of $>10$ viable eggs $[1 / 20$ to $1 / 50$ of a single cyst] is highly unlikely) was established on the basis of Dutch PCN populations scored as nonviable. The confidence level of $99.7 \%$ was chosen by the authors of this article and does not necessarily reflect a degree of certainty that is required for statutory purposes. If desired, the detection threshold of this assay could be optimized further by reducing the background signal produced by non-target soil components (e.g., by sample purification). Implementation of this methodology should be preceded by the analysis of local PCN populations. In combination with the desired confidence level, this would result in a new threshold value that might deviate from the value presented here.

Presumably, this viability assay can be used as well for other high-impact cyst nematode species such as Heterodera glycines, $H$. schachtii, or $H$. avenae. It is conceivable that this principleexploiting the loss of selective permeability of membranes upon death-can also be used to determine the viability of survival propagules of other plant pathogens and animal parasites.

\section{ACKNOWLEDGMENTS}

We thank the Dutch FES program "Strengthening Plant Health Infrastructure", subprogram: "Plant pathogen viability" for financial support; the NAK Emmeloord and Plant Research International (Bio-interactions unit) for their kind supply of well-characterized batches of viable and nonviable PCNs; and A. Hakman and P. van Haperen-both M.Sc. student at Wageningen University-for their help in the experiment on DNA survival in soil.

\section{LITERATURE CITED}

1. Amjad, M., Kfoury, N., Cha, R., and Mobarak, R. 2004. Quantification and assessment of viability of Cryptococcus neoformans by LightCycler amplification of capsule gene mRNA. J. Med. Microbiol. 53:1201-1206.

2. Anonymous. 2009. Globodera rostochiensis and Globodera pallida. EPPO Bull. 39:354-368.

3. Arntzen, F. K., Mulder, J. G., and Visser, J. H. M. 1994. Rapid and nondestructive assessment of the number of eggs in cysts of potato cyst nematodes by weighing. Fundam. Appl. Nematol. 17:299-302.
4. Boyd, A. E. W. 1941. Determination of death in the larvae of the potato root eelworm. Nature 148:782.

5. Chastain, T. G., and King, B. 1990. A biochemical method for estimating viability of teliospores of Tittetia controversa. Phytopathology 80:474476.

6. Chaudhuri, N., Dick, R. I., Engelbrecht, R. S., and Austin, J. H. 1966. Staining of free-living nematodes by eosin-Y dye. Nematologica 12:337342.

7. Clarke, A. J., Perry, R. N., and Hennessy, J. 1978. Osmotic stress and the hatching of Globodera rostochiensis. Nematologica 24:384-392.

8. Den Ouden, H. 1960. Periodicity in spontaneous hatching of Heterodera rostochiensis in soil. Nematologica (Suppl.) II:101-105.

9. Devine, K. J., Dunne, C., O'Gara, F., and Jones, P. W. 1999. The influence of in-egg mortality and spontaneous hatching on the decline of Globodera rostochiensis during crop rotation in the absence of the host potato crop in the field. Nematology 1:637-645.

10. Folkertsma, R. T., Helder, J., Gommers, F. J., and Bakker, J. 1997. Storage of potato cyst nematodes at $-80^{\circ} \mathrm{C}$. Fundam. Appl. Nematol. 20:299-302.

11. Higashiyama, T. 2002. Novel functions and applications of trehalose. Pure Appl. Chem. 74:1263-1269.

12. Holterman, M., van der Wurff, A., van den Elsen, S., van Megen, H., Bongers, T., Holovachov, O., Bakker, J., and Helder, J. 2006. Phylumwide analysis of SSU rDNA reveals deep phylogenetic relationships among nematodes and accelerated evolution toward crown clades. Mol. Biol. Evol. 23:1792-1800.

13. Hoppe, R. W., and Bavister, B. D. 1984. Evaluation of the fluorescein diacetate (FDA) vital dye viability test with hamster and bovine embryos. Anim. Reprod. Sci. 6:323-335.

14. James, C. E., and Davey, M. W. 2007. A rapid colorimetric assay for the quantitation of the viability of free-living larvae of nematodes in vitro. Parasitol. Res. 101:975-980.

15. Janssen, R., Bakker, J., and Gommers, F. J. 1987. Circumventing the diapause of potato cyst nematodes. Neth. J. Plant Pathol. 93:107-113.

16. Kaucner, C., and Stinear, T. 1998. Sensitive and rapid detection of viable Giardia cysts and Cryptosporidium parvum oocysts in large-volume water samples with wound fiberglass cartridge filters and reverse transcriptionPCR. Appl. Environ. Microbiol. 64:1743-1749.

17. Kobayashi, H., Oethinger, M., Tuohy, M. J., Hall, G. S., and Bauer, T. W. 2009. Unsuitable distinction between viable and dead Staphylococcus aureus and Staphylococcus epidermidis by ethidium bromide monoazide. Lett. Appl. Microbiol. 48:633-638.

18. Lee, J. L., and Levin, R. E. 2006. Use of ethidium bromide monoazide for quantification of viable and dead mixed bacterial flora from fish fillets by polymerase chain reaction. J. Microbiol. Methods 67:456-462.

19. MacMillan, K., Blok, V., Young, I., Crawford, J., and Wilson, M. J. 2006. Quantification of the slug parasitic nematode Phasmarhabditis hermaphrodita from soil samples using real time qPCR. Int. J. Parasitol. 36:1453-1461.

20. Mulder, J. G., Diepenhorst, P., Plieger, P., and Brueggemann-Rotgans, I. E. M. 1996. Hatching agent for the potato cyst nematode C. P. I. Luxan. The Netherlands. Patent US 5585505 (A).

21. Ogiga, I. R., and Estey, R. H. 1974. The use of Meldola's blue and Nile blue a, for distinguishing dead from live nematodes. Nematologica 20:271-276.

22. Stockwell, M. P., Clulow, J., and Mahony, M. J. 2010. Efficacy of SYBR 14/propidium iodide viability stain for the amphibian chytrid fungus Batrachochytrium dendrobatidis. Dis. Aquat. Org. 88:177-181.

23. Watanabe, M. 2006. Anhydrobiosis in invertebrates. Appl. Entomol. Zool. 41:15-31.

24. Womersley, C., and Smith, L. 1981. Anhydrobiosis in nematodes I. The role of glycerol, myo-inositol and trehalose during desiccation. Comp. Biochem. Physiol. 70B:579-586. 